\title{
Massive haematemesis and melaena from a Meckel's diverticulum
}

\author{
SUNIL SHAUNAK* \\ B.Sc., M.B., B.S.
}

JOHN O'DONOHUE

F.R.A.C.S., F.R.C.S.

Epsom District Hospital, Dorking Road, Epsom, Surrey KT18 7EG

\begin{abstract}
Summary
A case of Meckel's diverticulum in a middle-aged man presenting acutely with haematemesis and melaena is reported. Such a presentation has not to our knowledge been previously reported in this age group.
\end{abstract}

KEY WORDS: massive haematemesis and melaena, Meckel's diverticulum.

\section{Introduction}

Rectal bleeding is the commonest presenting symptom following haemorrhage in a Meckel's diverticulum (Weinstein, Cain and Remine, 1962; Soderlund, 1959). We report a case of massive haematemesis and melaena in a middle-aged man with no previous symptoms, a presentation which has not to our knowledge been previously recorded in this age group.

\section{Case report}

A 48-year-old man who had previously been well was admitted with melaena. He had woken that night with tenesmus and noticed dark-coloured blood in his stool. He had also vomited twice but no blood was present. His past medical history included aspirin ingestion 3-4 times a week for headache for many years, and he had taken 3 aspirin tablets in the $12 \mathrm{hr}$ before admission.

On examination, he was not shocked, with a pulse of $70 / \mathrm{min}$, blood pressure $130 / 55 \mathrm{mmHg}$, non-tender abdomen and a maroon-coloured stool on rectal examination. His haematological indices were normal.

Two hours after admission, he became shocked with a rapid thready pulse of $125 / \mathrm{min}$, BP $65 / 20$ $\mathrm{mmHg}$ and the loss of approximately 1 litre of maroon-coloured blood per rectum. The patient was resuscitated with blood, only to have a second large loss of maroon-coloured blood rectally $2 \mathrm{hrs}$ later. His haemoglobin had fallen from $12 \cdot 8$ to $8 \mathrm{~g} / \mathrm{dl}$.

*Present address: City Hospital, Greenbank Drive, Edinburgh E10 5SB.
Six hours after admission, he started passing frest blood per rectum, and had a large haematemesis vomiting approximately $150 \mathrm{ml}$. An emergenc $\bar{B}$ laparotomy was performed which revealed a stór mach, duodenum and small bowel full of bloof Gastroduodenotomy failed to elicit a lesion in the stomach or proximal duodenum. The only cause found for the bleeding was an $8 \mathrm{~cm} \times 3 \mathrm{~cm}$ Meckel diverticulum, $55 \mathrm{~cm}$ from the ileo-caecel valve. The diverticulum was excised with ileal resection. Histom logy revealed ectopic gastric and colonic mucosa if the diverticulum with a chronic $7 \mathrm{~mm}$ ulcer in th jejunal wall adjacent to the Meckel's diverticulum: The patient subsequently made a satisfactory post operative recovery.

\section{Discussion}

Meckel's diverticulum has been found in retros spective studies to occur in $0.8-4 \%$ of the population (Williams, 1981). Soltero and Bill (1976), using lifeä table techniques, have calculated the risk of complie cations in the 40-50-year-old age group to be $1.5 \% \overrightarrow{\overrightarrow{0}}$

Our patient was unusual in that he had previously never had any symptoms from his diverticulum, his presentation being acute. Brown and Ellis (1980). have reported a case of haematemesis and melaena in a 30-year-old man who had a long history of central. abdominal ache since childhood and whose acute symptoms of intermittent melaena and haematemes occurred over a period of 3 days. Laparotom 9 revealed a leiomyoma in the diverticulum with blood up to mid-ileal level. Moore and Johnston (1976 reported 2 cases in adults in their series but offer no details.

Haemorrhage occurs from a terminal branch of the superior mesenteric artery, which crosses the ileum to supply the diverticulum. Such bleeding manifest: itself as melaena rather than haematemesis despite the rate of bleeding. However, as our case show haematemesis does not exclude a diagnosis of bleede ing Meckel's diverticulum and this should always be considered in cases where there is no apparent source 
of upper gastrointestinal bleeding. Small bowel enemas and technetium pertechnetate isotope scans are of little value in acute cases such as ours, but mesenteric angiography has been shown to be of benefit, and may be of use in making a pre-operative diagnosis (Hall, 1975).

Bleeding diverticulae are usually associated with gastric mucosa either in the diverticulum or in the adjacent ileal mucosa, and so are best removed by ileal resection rather than diverticulectomy.

A history of aspirin ingestion is often found in those presenting with upper gastrointestinal bleeds. Our patient had a long history of regular aspirin ingestion, but it would be difficult to evoke a causal association. Ordinary aspirin preparations are absorbed largely from the stomach, but certain enteric coated preparations (used for long-term medication) are absorbed in the small bowel with absorption being delayed for $6 \mathrm{hr}$ or more (Lawrence, 1980). Future studies may usefully look more carefully for such an association. Two cases of intestinal perforation distal to the duodenal have been reported in patients on Osmosin (continued release indomethacin) (Committee on Safety of Medicines, 1983).

The number of Meckel's diverticulae diagnosed pre-operatively is very small. Ymaguchi's (1978) review of all Japanese cases found a rate of $5.7 \%$ and Moore and Johnston's study (1976) notes that none was diagnosed correctly.

We wish to emphasize the importance of a high index of suspicion for Meckel's diverticulum in all cases of haematemesis and melaena. Furthermore, any obscure cause of intestinal bleed should suggest the possibility of a complicated diverticulum.

\section{Acknowledgment}

We wish to thank Mr S. E. P. Miller for his permission to report this case.

\section{References}

Brown, I.W. \& Ellis, H. (1980) Two cases of gastro-intestinal bleeding. British Journal of Clinical Practice, 34, 301.

COMMITTEE ON SAFETY OF MEdicines (1983) Current problems. No. 11. (August).

HaLL, T.J. (1975) Meckel's bleeding diverticulum diagnosed by mesenteric arteriography. British Journal of Surgery, 62, 882.

LAWRENCE, D.R. (1980) Clinical Pharmacology 5th edn., p. 425. Churchill Livingstone, Edinburgh.

MOORE, T. \& JOHNSTON, A.O.B. (1976) Complications of Meckel's diverticulum. British Journal of Surgery, 63, 453.

SODERLUND, S. (1959) Meckel's diverticulum: a clinical and histological study. Acta chirurgica scandinavica (Suppl.) 1959, 248 (Suppl.), 1.

SOLTERO, M.J. \& BILL, A.M. (1976) The natural history of Meckel's diverticulum and its relation to incidental removal. American Journal of Surgery, 132, 168.

Weinstein, E.C., CAIN, J.C. \& Remine, W.H. (1962) Meckel's diverticulum. Journal of the American Medical Association, 182, 251.

WILliams, R.S. (1981) Management of Meckel's diverticulum. British Journal of Surgery, 68, 477.

YMAGUCHI, M. (1978) Meckel's diverticulum. An investigation of 600 patients in Japanese literature. American Journal of Surgery, 136, 247.

(Accepted 12 January 1983) 